\title{
Informal Logic and the Theory of Reasoning
}

\section{Maurice A. Finocchiaro University of Nevada at Las Vegas}

Informal logic seems to be suffering from an image problem, a bad conscience, and an identity crisis. The image problem derives from the somewhat negative connotations of the term "informal," which often conveys the impression that what we have here is a sloppy, nonserious approach to the study of logical problems. ${ }^{1}$ The bad conscience stems from conceiving the field as the theory of informal fallacies, and then taking the notion of "theory" to be such as to imply that a theory worthy of the name is necessarily formal; 2 this would make the label "informal logic" a disguise for the formal theory of those fallacies different from the deductive and inductive ones. These two views are, respectively, a methodological interpretation of informal logic in terms of its alleged approach ("informality"), and a substantive definition in terms of its alleged subject matter, ("informal fallacies"); now, since it is not easy to devise alternative interpretations as long as one keeps close to the terminological and verbal level, 3 this may lead to the identity crisis of wondering what on earth informal logic is supposed to be. In this paper I plan to bypass these difficulties by conceiving informal logic as the theory of reasoning. By theory of reasoning I mean the attempt to formulate, to test, to clarify, and to systematize concepts and principles for the interpretation, the evaluation, and the sound practice of reasoning. I claim that the theory of reasoning so defined is a legitimate philosophical enterprise which is both viable and important, and that it corresponds to the central theoretical 4 concerns of those who explicitly identify themselves with the field of informal logic, but that it also suggests certain constructive criticisms and desirable reforms in this discipline.

Let me begin by clarifying my definition of the theory of reasoning. First, notice that I speak of reasoning, rather than, for example, argumentation; this is deliberately meant to allow a broader domain, by including, besides the study of arguments, such activities as problem-solving, decisionmaking, persuasion, and explaining, which cannot be equated with argumentation, but which may involve reasoning in an essential way. The emphasis on reasoning is also meant as a reminder that what is being studied here is a mental activity that actually occurs in the world and which leaves empirical traces (normally in the form of written or oral discourse). This in turn means that the theory of reasoning has an empirical orientation and is not a purely formal or abstract discipline.

Second, you should notice my explicit reference to the interpretation of reasoning. This is needed partly for the intrinsic reason that such interpretation aims at the understanding of reasoning, and the understanding of a phenomenon is obviously an essential concern of any theorizing. However, I also emphasize it in order to correct what 1 feel is an overconcern with evaluation; this imbalance is shown, for example, by the fact that informal logic textbooks often define logic as the attempt to distinguish good from bad arguments, and by the fact that no explicit mention of interpretation is made in Johnson and Blair's definition given at the First International Symposium of Informal Logic. 5 Therefore, the interpretative dimension needs distinct recognition despite the fact that we would all agree that it is indirectly mentioned by the evaluative dimension, insofar as the proper evaluation of an argument presupposes that it has been properly interpreted 6

My third clarification involves the inclusion of concepts and principles for the sound practice of reasoning. Notice that I am not talking about important or original reasoning, but merely about correct reasoning. Principles for reasoning well would obviously be related to principles for the evaluation of reasoning. Nevertheless the difference remains since the activity of evaluation would normally come after a certain argument has been produced, whereas the practice of reasoning means simply the construction of actual arguments or the actual involvement in reasoning. In this regard, both interpretation and evaluation have something in common which they do not share with practice; they are both reflection on 
previous practice, whereas the practice of reasoning is the construction of what can later become the subject of those types of reflection.

Another important feature of my definition is that I speak of concepts and principles. Notice that I do not say "universally valid principles," hence it is an open question whether any of them exist. It not, it would be part of the task of the theory of reasoning to tell us that the most we can hope for are principles of restricted application and limited validity, as well as to specify which principles hold in which fields. ${ }^{7}$ Moreover, because of the distinction between interpretation and evaluation, my definition also leaves it as an open question whether there are universally valid principles of interpretation, even if it turns out that there are no universally valid principles of evaluation. Additional openness is allowed by my reference to concepts, as well as to principles. In fact, a concept may be useful for interpreting, evaluating, or practicing reasoning, even though there might be disagreement about which principles or which types of principles formulated in its terms are the correct ones. For example, one might agree that the notion of ad hominem argument is important at least as a way of classifying certain types of reasoning, but one does not have to agree with Henry Johnstone's metaphilosophical principle of interpretation that all genuinely philosophical arguments are ad hominem, 8 nor with the widely accepted principle of evaluation that ad hominem arguments are fallacious.

Finally, I should clarify that, in saying that the theory of reasoning aims to formulate, test, clarify, and systematize principles, I am indeed referring to four distinct activities. Obviously, systematization is impossible unless the principles in question have already been formulated and have undergone a certain amount of testing and clarification. Moreover, there is no reason to expect the same degree of systematization that was possible for Euclidean geometry or celestial mechanics. Nevertheless, although one of the greatest temptations to be resisted is that of premature systematization, the idea of systematization is not excluded in principle. The reference to testing reflects the semi-empirical orientation mentioned earlier, and it can mean either confirmation or disconfirmation. A good example of disconfirmation is Professor Hintikka's criticism that the quantification theory of symbolic logic is neither a correct description of nor a correct abstraction from natural-language reasoning with quantifiers, ${ }^{9}$ while a good example of confirmation would be $L$. Jonathan Cohen's demonstration that probabilistic reasoning by juries in Anglo-American courts conforms to a number of principles which embody an inductive, neo-Baconian, non-Pascalian notion of probability. 10 Last, the clarification of principles is distinct from their formulation, as shown for example by the fact that, regardless of who was the first to formulate explicity the Principle of Charity, additional insights have been provided by Ralph Johnson's recent discussion in the Informal Logic Newsletter. 11

I claimed above that the theory of reasoning so conceived represents a critical systematization of work in the field of informal logic. In order to justify directly this claim one would have to argue that the main concerns of informal logicians can find a place, or can be improved by corresponding investigations, in the theory of reasoning. However, the sketch just given is sufficient to suggest a considerable overlap between the two; hence I will postpone for the moment a direct comparison, and I will go on to add further indirect evidence for their correspondence by discussing the question of the philosophical legitimacy of the theory of reasoning. This discussion will take the form of answers to various objections.
The most fundamental objection to the theory of reasoning is that the alleged entity which is the subject matter of its inquiries does not really exist. 12 Reasoning is presumably an epiphenomenal illusion deriving from using a general label to refer to a number of disparate activities. A theory of reasoning per se, as distinct from theorizing about particular instances or types or fields of reasoning, makes no more sense than a theory of success in general; just as success in one field (say business) is very different trom success in ariother field (say sports), so is the skill of legal reasoning, for example, different from that of scientific reasoning. Even a general-sounding type of success, like Dale Carnegie's winning friends and influencing people, is not truly universal since it is obvious that one could master this art and yet fail at such things as sports, teaching, military strategy, debating, poetry, etc. Hence, even if the entity sometimes labeled everyday reasoning turns out to be theoretically and critically comprehensible (taking this label to refer to reasoning about such practical and fundamental issues that deserve the attention of every educated person). even then the theory of everyday reasoning would not be equivalent to the theory of reasoning simpliciter, since the nature of everyday reasoning would be bound to differ from the nature of reasoning in such special domains as science, the law, medicine, business, etc.

My answer to this powerful objection consists of a countercharge and a constructive suggestion. The counter-charge is that the criticism confuses the interpretation and the evalua. tion of reasoning, and that in effect it overstresses the latter This is shown by the tendency of these critics to compare reasoning with such implicitly evaluated entities as success, creativity, constructiveness, and effectiveness, 13 whereas the proper analogue to such nongeneralizable nonentities would be correct reasoning. In other words, these critics ignore the fact (which they themselves admit 14) that "reasoning" is both a task and an achievement term; to engage in reasoning does not necessarily imply to be successful at it. This means that, at. worst, what's impossible is a general theory of correct reasoning, and not necessarily a general interpretative theory of the structure of reasoning. However, even the limited pessimistic conclusion seems excessively apriorist, since, given that it would allow for limited theories of correct reasoning in particular fields, there is no a priori reason to predict that the further generalization and systematization of these limited theories will necessarily fail. Moreover, the notion of a field of reasoning is problematic, 15 and the same criticism made against the possibility of generalizations among fields could be leveled against the possibility of generalizing within a given field, which after all consists of various sub-fields. Finally, it is possible that a general theory of evaluation might be based in part on a general theory of interpretation, whose possibility, as we have seen, is untouched by the present criticism. But this brings us to the question of what all types and instances of reasoning have in common, and it is here that my constructive suggestion becomes relevant. I think that the essential feature of all reasoning is the interrelating of individual thoughts in such a way that some follow from others, 16 and that the normal linguistic expression of such interrelated thinking involves the use of particles like "because," "therefore," etc. However minimal this conception is, it allows the theory of reasoning to get started by suggesting that we try to understand and to evaluate those discourses having a high incidence of these logical particles.

If this first objection to the legitimacy of the theory of reasoning threatens to deprive it of a genuine subject matter, a second criticism threatens to let a discipline other than philosophy lay claim upon that domain. The objection would 
now be that there already exists a branch of cognitive psychology, namely the psychology of reasoning, that theorizes about the phenomenon in an a posteriori fashion. What then is the difference, if any, between the psychology of reasoning and the philosophical theory of reasoning?

Let me begin answering this objection by noting that at a phenomenological level there are certainly some differences. To be specific, psychologists tend to be experimental, to refrain from explicit evaluation, and to favor explicit explanations in terms of theoretical models of unconscious mental processes.

Their experimental approach may be viewed as their way of being empirical, and it may be constrasted with the philosophers' historical method, which is another kind of empirical orientation. In other words, psychologists tend to establish contact with the real world of reasoning by making experiments in which human subjects are asked to perform various tasks which involve reasoning in one form or another; on the other hand, philosophers tend to study reasoning that has already taken place and left historical traces, usually in the form of written records. One may question the soundness of the experimental approach since the data thereby collected reflect the artificiality of the experimental situation; that is, the reasoning in which the experimental subjects are led to engage is necessarily aritificial since their reasoning is taking place solely as a result of their participation in the experiment and the experimenter's instructions; thus, one may be reluctant to generalize or extrapolate that whatever features human reasoning exhibits during experiments, will also characterize it in real-life situations. Now, this difficulty with the experimental approach might lead one to claim that if psychologists wanted to be properly empirical, then they should adopt the historical approach favored by philosphers; 17 however, such a proposed reform would not obliterate the surface difference that presently exists between the two'enterprises.

It is perhaps in order to neutralize this criticism of the experimental approach that psychologists are also inclined to devise models of mental processes that explain the experimental data they collect. I believe the connection would be that if the cognitive performance shown by experimental subjects is the effect of the mental processes postulated to explain it, and if these explanation-providing processes are sufficiently basic and general, then one is entitled to say that the latter processes possess a robust reality, firm enough to prevent variation from an experimental to a real-life situation. In short, if during the experiments what is happening inside the minds of the subjects is of the appropriate sort, then the same things would have to happen outside the experimental situation. Whatever the soundness of these claims, my main concern is to emphasize the difference from the philosophical theory of reasoning. I think the central difference is that the explanatory mental models devised by psychologists normally involve processes of which the human reasoners are not in fact or could not in principle be or become conscious. By contrast, the philosopher who is trying to understand reasoning does so in terms of conscious or potentially conscious processes; for example, unstated assumptions may be originally overlooked in a given argument, but they are certainly entities that can be brought before the mind as a result of discussion.

The third surface difference between the psychology and the philosophy of reasoning concerns evaluation. It is explicitly included in my definition of the theory of reasoning, and it obviously corresponds to the philosophers' practice of assessing the validity, soundness, or correctness of the reasoning they examine. By contrast, psychologists like to follow a sup- posedly value-free approach; they pretend that they are merely describing and explaining the cognitive phenomena they observe. Even when they claim to have found evidence that human beings reason in various specific illogical or irrational ways, 18 psychologists adopt a curiously nonevaluative stance, for they treat this alleged irrationality as a fact-to-be-explained, rather than as a condition to be avoided, and they take this irrationality merely to mean an objective discrepancy between the performance of experimental subjects and various abstract principles taken from truth-functional logic, the mathematical theory of probability, etc. Clearly the real difference is one of explicitness, rather than presence or absence, of evaluation.

Actually, this leads to another difference from the point of view of evaluation. Once we see that the real fact established by psychologists is the discrepancy between human reasoning and the principles of traditional formal deductive and inductive logic, there is no reason to prefer an evaluative conclusion about human irrationality to one about the empirical unfoundedness of formal logic. In fact, given an empirical orientation, it seems clear that the discrepancy should be resolved by a negative evaluation of the traditional logical principles. This is precisely what L. Jonathan Cohen has been doing in the domain of probabilistic reasoning, where he has attempted to devise a non-Pascalian theory of probability more in conformity with the actual performance of human beings. 19

So we may summarize the evaluational differences between the psychology and the philosophy of reasoning by saying that whereas psychologists evaluate reasoning only im. plicitly and unavoidably, philosphers do so actively and explicitly; moreover, psychologists' evaluations are directed against the performance of their experimental subjects, whereas philosophers' evaluations tend to be directed against traditional formal logic. Together with the difference between an experimental and an historical approach, and between the use of nonconscious and of potentially conscious mental processes, these are certainly sufficient to distinguish the two fields of endeavor. I should end this section by saying that there is no reason, however, why philosophers cannot adopt and appropriate useful facts or ideas examined by psychologists. Besides the discrepancy between actual cognitive performance and formal logic, another very important fact for which there seems to be overwhelming evidence is that in general the content of propositions has a significant effect on how people interpret their logical form, and in particular the concreteness or the abstractness of the subject matter sometimes facilitates and sometimes hinders their reasoning. 20

Another sweeping criticism that can be leveled against the legitimacy of the theory of reasoning raises questions about "argument analysis as a plausible subject for study." 21 What is called argument analysis in the literature is indeed the heart of the theory of reasoning since it largely corresponds to what I call the interpretation and the evaluation of reasoning. For example, of Michael Scriven's seven steps of argument analysis, 22 the first three obviously pertain to interpretation since they are, respectively, the clarification of meaning, the identification of conclusions, and the portrayal of structure; the last three obviously deal with evaluation since they speak of the criticism of the premises and of the inferences, the introduction of other relevant arguments, and the overall evaluation of the given argument; the fourth step is the formulation of unstated assumptions or missing premises, and I would regard it as being partly an interpretative and partly an evaluative problem. What supposedly undermines the viability of argument analysis are the following three things. First, the three interpretative steps are neither sequential nor discrete 
since it is clear that each presupposes the other two: for example, one cannot understand the meaning of an argument and of its parts without knowing the identity of its conclusion and how its various components are structured into a whole. ${ }^{23} \mathrm{Se}-$ cond, it is clear that the articulation of unstated assumptions is a task that requires creativity and imagination, and hence the procedure is neither mechanical nor methodical.24 Finally, the evaluation process presupposes substantive and factual information which cannot be regarded as logical in any sense of the term (including the sense of the phrase "informal logic"); this is obvious from the step that requires criticism of the premises and the one that asks us to introduce other relevant arguments.

1 agree with almost all of these points, with one very important exception. The final conclusion of this critical argument simply does not follow, that is the conclusion that argument analysis and the theory of reasoning are not a serious or plausible subject for study. In order to infer this conclusion one would have to assume that the only serious or plausible disciplines are those that possess techniques and procedures that are simple, effective, and mechanical. There are many difficulties with this assumption. Partly it seems to advocate an untenable scientism according to which the only subjects worthy of pursuit are the exact sciences. Partly it seems to leave the door open for the kind of irrationalism that the proponents of the new rhetoric have been reacting against, 25 namely that intellectual respectability is to be equated only with effective decision procedures, and all else is equally worthless. Obviously the proper thing to do, when mechanical methods are not available, is to elaborate the imperfect rules of thumb that are possible. And partly such an assumption seems to ignore even the well known limitations of mathematics and formal logic stemming from Godel's theorems; for example, there is no mechanical procedure to construct derivations of theorems in the predicate calculus. In summary, I would say that this objection reflects an inadequate epistemology and philosophy of science.

The last objection I want to discuss is one to which I am not sure I can give an effective rebuttal. It stems from the theory/practice distinction. The difficulty is that, despite its empirical, practical, and contextual orientation, and despite its sensitivity to concrete reasoning in natural language, the theory of reasoning is still a theoretical inquiry whose concepts and principles, however sound and low-level, need to be applied and used in practice in ordinary contexts different from that of philosophical reflection. This is simply an instance in the domain of reasoning of a general difficulty that seems to afflict the most diverse fields. For example, if one looks at science, the greatest examplars of scientific practice are such people as Galileo, Newton, Lavoisier, and Einstein, whereas the most outstanding theorists of science are such people as Bacon, Peirce, Duhem, Popper, etc.; in politics we find, on the one hand, Pericles, Caesar Augustus, Jefferson, Disraeli, etc., and on the other hand, Aristotle, Machiavelli, Tocqueville, etc.; in morality, one group would include Socrates, St. Francis, Gandhi, etc., the other Aristotle, Kant, Bentham, etc. Why should we expect the situation to be any different in the domain of our present interest?

This difficulty can also be elaborated in another way. From the point of view of reasoning, the theory of reasoning is at best an instance of a special kind of reasoning, namely reasoning about reasoning. What reason is there to think that if one becomes proficient in reasoning about reasoning, one will be also proficient in reasoning about atoms and molecules, torts and contracts, personal and emotional problems, affirmative action and nuclear deterrence, etc.? When expressed in these terms, this objection may be reminiscent of the earlier one about whether there is any such thing as reasoning in general. However, what we have here is a new difficulty, since we are now asking whether there is any significant similarity between, for example, reasoning about reasoning and reasoning about atoms and molecules, whereas earlier we were asking whether there is any significant similarity between such things as reasoning about atoms and molecules and reasoning about torts and contracts. Someone could admit that there are significant similarities among fields at the object level, but not between the object level and the metalevel, or one might think that each field is significantly different from each other, but argue that, for example, object-level reasoning about atoms and metalevel reasoning about reasoning about atoms do not constitute two different fields. But the transference between these two levels is what the present objection questions, or to be more exact, the transference from the higher into the lower level.

In order to begin answering this objection, I would want to say that the divergence between theory and practice mentioned above does not show that the theoretical reflections of the practitioners, or the actual behavior of the theorists, are inadequate, but only that normally they do not excel. Second, even from the point of view of excellence, there are exceptions to this generalization. For example, Socrates is not only a model of moral life, but a brilliant ethical theorist; Galileo is not only "the father of modern science," but also an acute methodological theorist; and both Socrates and Galileo were nonnegligible theorists of reasoning, as well as effective practitioners of reasoning. 26 Third, I should call attention to one element of my definition of the theory of reasoning which I have already mentioned, but without the proper emphasis. I defined the enterprise in terms of concepts and principles, not only for the interpretation and the evaluation of reasoning, but also for the "sound practice" of reasoning. Although the amount of theoretical understanding such principles for reasoning well provide is in inverse proportion to the ease of their practical applicability, some of them can certainly be formulated in such a way as to be easily applicable. Fourth, the objection seems stronger than it is only if we emphasize a necessary connection between proficiency in theory and proficiency in practice, for it is clear that there is no necessary connection. However, if we are more realistic and speak in terms of likely influence, then I think we can say that proficiency in certain kinds or aspects of theorizing is likely to improve practice, and conversely proficiency in actual reasoning is likely to produce the desire for theoretical reflection in order to understand better what one is doing. Finally, theory and practice are not themselves inert, static entities, and so, to the extent that there is a lack of correspondence, one can demand that they be brought closer together, that theory be constructed with an eye toward practice, and that practice be more infused with theory.

To sum up, I have addressed myself to the problem of giv. ing a positive, constructive, and self-sufficient interpretation of informal logic, by viewing it as a philosophical approach tc the theory of reasoning. I began by defining the theory of reasoning in such a way as to avoid apriorism, excessive evaluationism, dogmatic universalism, and premature systematization. And then I defended the viability, the philosphical character, and the methodological legitimacy of the theory of reasoning so conceived by defending it from a number of objections. These were the criticisms that its defin. ing subject matter-reasoning-is perhaps a fictitious one; that even if reasoning is not a fictitious subject matter, it can only be studied by a branch of cognitive psychology; that even it there is a distinct, philosophical way of studying reasoning, 
this is not a discipline that can be taken seriously, as the difficulties afflicting argument analysis show; and finally, that at any rate, the practical import of the theory of reasoning is suspect. Both my elaboration of the definition and $\mathrm{my}$ methodological justification of the theory of reasoning suggest a considerable overlap 27 with "informal logic." Two other ways of strengthening this suggestion have not been attempted in this paper. One would be a detailed examination of explicit contributions to informal logic to show that they could be interpreted as contributions to the theory of reasoning. $28 \mathrm{~A}$ second way of strengthening the suggestion would be to show how contributions to the theory of reasoning can be interpreted as contributions to informal logic, in the sense that they are addressing themselves to topics and issues of explicit concern and interest to informal logicians. 29

\section{Notes}

1. The first definition given by the Oxford English Dictionary for the word "informal" is: "Not done or made according to a recognized or prescribed form; not observing forms; not according to order; irregular; unofficial, disorderly" (1933 edition, vol. V. p. 273).

2. Here $I$ am thinking of the interpretation given in J. Woods, "What is Informal Logic?", in informal Logic: The First International Symposium, edited by J. Anthony Blair and Ralph H. Johnson (Inverness, CA: Edgepress, 1980), pp. 57-68. Woods is certainly right to distinguish between two senses of "formal": (1) the use of formal, mathematical, or symbolic techniques, and (2) formalization or the construction of logistic or axiomatic systems (p. 58). He is also correct in noting that, from the point of view of (2), even mathematics is typically informal; and so he is merely advocating (1). Nevertheless, it is questionable whether this can escape the present difficulty.

3. What I mean here is that if we take the label "informal logic" too seriously, and then we try to examine its meaning and uses, we could not ignore the sense given to the term in Gilbert Ryle, "Formal and Informal Logic," in his Dilemmas (Cambridge: Cambridge University Press, 1954), pp. 111-29. For Ryle informal logic is essentially identical to ordinary language philosophy, or to be more exact, to the analysis of the "logic" of concepts like pleasure, memory, responsibility, chance; whereas formal logic is the study of concepts such as "all," "some," "not," etc.

4. In speaking of the theoretical concerns of "informal logicians," I mean to distinguish them from practical concerns. In fact, as Michael Scriven stressed at the Second International Symposium on Informal Logic, informal logic cannot be equated with the theory of reasoning simpliciter, any more than medicine can be equated with the theory of healing; just as medicine includes the activity of actually curing diseases, so informal logic refers to the activity of formulating actual arguments. What this means is that informal logic must be taken to refer both to the theory and practice of reasoning. This, in turn, introduces further complications, some of which will be discussed below, toward the end. For other developments, see Maurice A. Finocchiaro, Galileo and the Art of Reasoning (Boston: Reidel, 1980), especially pp. 299-302, where a different twist is given to Scriven's point, by introducing the notion of reasoning about reasoning, as a helpful way of combining the theory and the practice of reasoning.
5. Cf. Informal Logic, p. 3.

6. For an explicit discussion of this presupposition, see for example, John E. McPeck, Critical Thinking and Education (New York: St. Martin's Press, 1981), p. 63, and Finocchiaro, Galileo and the Art of Reasoning, pp. 339-40.

7. As also discussed below, this answers some of the explicit and implicit objections found in McPeck's Critical Think. ing and Education.

8. Henry W. Johnstone, Jr., Validity and Rhetoric in Philosophical Argument (University Park, PA: Dialogue Press, 1978).

9. Jaakko Hintikka, "Quantifiers vs. Quantification Theory," Linguistic Inquiry, 5(1974): 153-77, reprinted in Game-Theoretical Semantics, edited by Esa Saarinen (Dordrecht: Reidel, 1979), pp. 49-79.

10. L. Jonathan Cohen, The Probable and the Provable (Oxford: Clarendon Press, 1977); idem, "Subjective Probability and the Paradox of the Gatecrasher," Arizona State Law Journal, 1981, pp. 627-34.

11. Ralph H. Johnson, "Charity Begins at Home," Informal Logic Newsletter, vol. iii, no. 3, pp. 4-9.

12. McPeck, Critical Thinking and Education, especially pp. 84-85. McPeck is directly concerned with teaching, and so he might not endorse my adaptation of his criticism to the context of theorizing. The same qualification applies to some of the other objections discussed below which stem from his book.

13. McPeck, pp. 84-85.

14. McPeck, p. 13.

15. As has been shown by Ralph $H$. Johnson, "Toulmin's Bold Experiment," Informal Logic Newsletter, vol. iii, no. 2, pp. 16-27, and vol. iii, no. 3, pp. 13-19.

16. For more details, see Finocchiaro, Galileo and the Art of Reasoning, especially Part III, p. 311.

17. This has been argued in Finocchiaro, op. cit., Chapter II.

18. P.C. Wason and P.N. Johnson-Laird, The Psychology of Reasoning (Cambridge: Harvard University Press, 1972); A. Tversky and D. Kahneman, "The Belief in the 'law of small numbers'," Psychological Bulletin, 76(1971): 105-110; idem, "Availability: A Heuristic for Judging Frequency and Probability," Cognitive Psychology, 5(1973); 207-32.

19. L. Jonathan Cohen, The Probable and the Provable, op. cit.; idem, "Can Human Irrationality be Experimentally Demonstrated?", The Behavioral and Brain Sciences, 4(1981): 317-70; idem, "Are People Programmed to Commit Fallacies? Further Thoughts About the Interpretation of Experimental Data on Probability Judgment," Journal for the Theory of Social Behavior, 12(1982): $251-74$. Finocchiaro follows a similar approach, though his context is that of the general theory of reasoning.

20. Wason and Johnson-Laird, Psychology of Reasoning, pp. 54-85, 193.

21. McPeck, p. 89.

22. Michael Scriven, Reasoning (New York: McGraw-Hill, 1976), pp. 39-51.

23. McPeck, pp. 87-89.

24. Ibid., p. 91

25. Ch. Perelman and L. Olbrechts-Tyteca, The New Rhetoric: A Treatise on Argumentation (Transl. J. Wilkinson and P. Weaver. Notre Dame: Univesity of Notre Dame Press, 1969), pp. 1-10.

26. The case of Socrates is, of course, well known, while for the case of Galileo the thesis is demonstrated in Finocchiaro's Galileo and the Art of Reasoning.

27. Notice that I speak of overlap, and not of identity, partly because, as clarified earlier, informal logic has a practical component which cannot be completely reduced to the theoretical one, even when the latter is required to in- 
clude the elaboration of principles for the sound practice of reasoning.

28. Cf. Maurice A. Finocchiaro, "Fallacies and the Evaluation of Reasoning," American Philosophical Quarterly, 18(1981): 13-22, where it is argued that the theories of fallacies prevalent among informal logicians are contributions (of various worth) to the theory of the evaluation of reasoning.

29. A possible example might be to elaborate the "informal logic" aspect of a work like Finocchiaro's Galileo and the
Art of Reasoning; cf. Ralph H. Johnson and J. Anthony Blair, "Informal Logic: The Past Five Years, 1978-1983," American Philosophical Quarterly, (forthcoming).

Maurice A. Finocchiaro, Department of Philosphy, University of Nevada at Las Vegas, 4505 Maryland Parkway, Las Vegas, Nevada, 89154

\section{announcement}

\section{Workshops on Teaching Human Values}

The Community College Humanities Association will sponsor a project featuring a series of two-day workshops this fall on the topic, "Teaching Human Values." The project is being supported, in part, by a grant from the Matchette Foundation. The workshops, to be held in Dallas (TX) and Secaucus (NI), will coincide with the 1984 annual meetings of the Southwestern and Eastern divisions of $\mathrm{CCHA}$. Individuals within all divisions, however, are encouraged to attend any one of the workshops.

The purpose of the workshops is to help faculty develop and teach courses and components of courses on ethical problems and issues involving human values. The workshops are designed especially for, but not limited to, faculty in the fields of philosophy, humanities, and social sciences. The programs of the workshops will focus on practical and successful approaches to the raising of human values within vocational and professional curricula.
The project is being developed by Professor Philip A Pecorino of Queensborough Community College, New York. Norman E. Bowie of the Center for the Study of Values will be the principal speaker and a workshop leader. Other workshop leaders will be nationally recognized experts and practitioners from non-philosophy disciplines as well as philosophy.

The dates, locations, and registration deadlines for the two workshops are as follows:

\section{Date Location Deadline}

October 26-27, 1984 Dallas, TX October 19, 1984

November 1-2, 1984 Secaucus, NJ October 26, 1984

The registration fee for each of the workshops is $\$ 50$.

For registration forms or further information, contact:

$$
\begin{gathered}
\text { Teaching Human Values } \\
\text { CCHA } \\
\text { Union County College } \\
1033 \text { Springfield Avenue } \\
\text { Cranford, NJ } 07016 \\
\text { (201) } 276-8136
\end{gathered}
$$

